\title{
Concomitants of Order Statistics from Bivariate Inverse Rayleigh Distribution
}

\author{
Muhammad Aleem \\ Department of Statistics, Islamia University Bahawalpur \\ Bahawalpur, Pakistan
}

\begin{abstract}
The probability density function (pdf) of the rth, $1 \leq r \leq n$ and joint pdf of the $r$ th and sth, $1 \leq r<s \leq n$ concomitants of order statistics are derived for Bivariate Inverse Rayleigh Distribution and their moments, product moments are obtained. Its percentiles are also obtained.
\end{abstract}

Keywords: Order Statistics, Concomitants of Order Statistics, Single and Product moments, Percentiles.

\section{Introduction}

Let $\left(X_{i}, Y_{i}\right), i=1,2,3,-----, n$ be $n$ pairs of independent random variables from some bivariate population with distribution function $F(x, y)$. If we arrange the $X$-variates in ascending order as $X_{1: n} \leq X_{2: n} \leq---\leq X_{n: n}$ then the $y$-variates paired (not necessarily in ascending order) with these ordered statistics are called the Concomitants of Order Statistics (David 1973), Induced Order Statistics (Bhatacharya 1984) and are denoted by $\mathrm{Y}_{[\mathrm{l:n}]}, \mathrm{Y}_{[2: \mathrm{n}]},---, \mathrm{Y}_{[\mathrm{n}: \mathrm{n}]}$. The probability density function (pdf) of $Y_{[r: n]}$ is given by (David 1981)

$$
g_{[r: n]}(y)=\int_{x} f(y / x) f_{r: n}(x) d x
$$

where $f_{r: n}(x)$ is the pdf of $X$ r:n which is given as:

$$
f_{r: n}(x)=C_{r: n}[F(x)]^{n-1}[1-F(x)]^{n-r} f(x)
$$

with $\quad C_{r: n}=\frac{n !}{(r-1) !(n-r) !}$

The joint pdf of the $Y_{[r: n]}$ and $Y_{[s: n]} 1 \leq r<s \leq n$ is

$$
g_{[r, s: n]}\left(y_{1}, y_{2}\right)=\int_{-\infty-\infty}^{\infty} \int_{2}^{x_{2}} f\left(y_{1} / x_{1}\right) f\left(y_{2} / x_{2}\right) f_{r, s: n}\left(x_{1} / x_{2}\right) d x_{1} d x_{2}
$$

Where $f_{r, s: n}\left(x_{1}, x_{2}\right)$ is the joint pdf of $\left(X_{r: n}, X_{s: n}\right)$ is given as:

$f_{r, s: n}\left(x_{1}, x_{2}\right)=C_{r, s: n}\left[F\left(x_{1}\right)\right]^{r-1}\left[F\left(x_{2}\right)-F\left(x_{1}\right)\right]^{s-r-1}\left[1-F\left(x_{2}\right)\right]^{n-s} f\left(x_{1}\right) f\left(x_{2}\right)$

with $\quad C_{r, s: n}=\frac{n !}{(r-1) !(s-r-1) !(n-s) !}$

For properties of concomitants of order statistics refer to David and Nagaraga (1998), Anguman and Khan (1998), Ahasanullah and Nevzoror (2001). More refer to Ayesha and Ahmad (2001) and Aleem and Ahmad (2003). 
Here we consider Bivariate Inverse Rayleigh distribution (Mukhergee and Saran 1984) with distribution function (df)

$$
\mathrm{F}=\mathrm{F}_{1} \mathrm{~F}_{2}\left(1+\alpha \overline{\mathrm{F}}_{1} \overline{\mathrm{F}}_{2}\right)
$$

with $\quad \bar{F}_{1}=1-F_{1}(x)$

and the pdf

$$
\mathrm{f}(\mathrm{x}, \mathrm{y})=\mathrm{f}_{1} \mathrm{f}_{2}\left[1+\alpha\left(1-2 \mathrm{f}_{1}\right)\left(1-2 \mathrm{f}_{2}\right)\right]
$$

with $\quad \mathrm{f}_{1}=\mathrm{F}_{1} \quad,-1 \leq \alpha \leq 1$

and $\quad \mathrm{f}(\mathrm{x}, \theta)=\frac{2 \theta}{\mathrm{x}^{3}} \exp \left[\frac{-\theta}{\mathrm{x}^{2}}\right] \quad \mathrm{x}, \theta>0$

$$
F(x)=\exp \left[\frac{-\theta}{x^{2}}\right]
$$

Expressions for single i.e rth and joint pdf of rth and sth concomitants of order statistics from bivariate inverse rayleigh distribution are obtained.

\section{Probability density function of $Y_{[r: n]}$}

For the Bivariate Inverse Rayleigh distribution with distribution function (1.5), the pdf of the rth concomitant of the order statistics, in view of (1.1) and (1.2) is:

$$
g_{[r: n]}(y)=4 \theta_{1} \theta_{2} C_{r: n} \frac{1}{y^{3}} e^{\frac{-\theta_{2}}{y^{2}}} \int_{0}^{\infty} \frac{1}{x^{3}} e^{\frac{-r \theta_{1}}{x^{2}}}\left[1-e^{\frac{-\theta_{1}}{x^{2}}}\right]^{n-r}\left[1+\alpha\left(1-2 e^{\frac{-\theta_{1}}{x^{2}}}\right)\left(1-2 e^{\frac{-\theta_{2}}{y^{2}}}\right)\right] d x
$$

where $\mathrm{y}, \theta_{1}, \theta_{2} \geq 0$

after integrating and simplifying, we get

$$
g_{[r: n]}(y)=\frac{2 \theta_{2}}{y^{3}} e^{\frac{-\theta_{2}}{y^{2}}} \sum_{i=0}^{n-r}(-1)^{i}\left(\begin{array}{c}
n-r \\
i
\end{array}\right) \frac{1}{(r+i)}\left[1+\frac{\alpha}{(r+i+1)}\left(1-2 e^{\frac{-\theta_{2}}{y^{2}}}\right)\right]
$$

where $\mathrm{y}, \theta_{2} \geq 0,-1 \leq \alpha \leq 1$

we have checked that $\int g_{[r: n]}(y) d y=1$

\section{Single Moments}

The Kth moment of $\mathrm{y}_{[\mathrm{r}: \mathrm{n}]}$, using the basic definition $\mu_{[\mathrm{r}: \mathrm{n}]}^{(\mathrm{k})}=\mathrm{E}\left[\mathrm{y}_{[\mathrm{r}: \mathrm{n}]}^{(\mathrm{k})}\right]$ of $(2.1)$ is obtained as:

$\mu_{[r: n]}^{(k)}=\sqrt{1-k / 2} \theta_{2}^{k / 2} C_{r: n} \sum_{i=0}^{n-r}(-1)^{i}\left(\begin{array}{l}n-r \\ i\end{array}\right) \frac{1}{(r+i)}\left\{1+\frac{\alpha}{(r+i+1)}\left(1-\frac{2^{k / 2}}{\theta_{2}}\right)\right\}$

(3.1) can be used to obtain moments and inverse moments (when $k=-k$ ). It is observed that the higher moments of order 2 or more for the distribution of the concomitant $y_{[r: n]}$ of rth order statistics does not exists but the inverse moments of any order exists. 
Concomitants of Order Statistics from Bivariate Inverse Rayleigh Distribution

4. Percentiles of $y_{[r: n]}$

The pth percentile of the concomitant of rth order statistics of Bivariate Inverse Reyleigh distribution is given as:

$$
\xi_{\mathrm{P}}=\left[\frac{2 \theta_{2} B}{\operatorname{Ln}\left\{A \pm \sqrt{A^{2}-4 B P}\right\}^{2}}\right]^{\frac{1}{2}}
$$

where

and

$$
\mathrm{A}=\mathrm{C}_{\mathrm{r}: \mathrm{n}} \sum_{\mathrm{i}=0}^{\mathrm{n}-\mathrm{r}}(-1)^{\mathrm{i}}\left(\begin{array}{c}
\mathrm{n}-\mathrm{r} \\
\mathrm{i}
\end{array}\right) \frac{1}{(\mathrm{r}+\mathrm{i})}\left[1+\frac{\alpha}{(\mathrm{r}+\mathrm{i}+1)}\right]
$$

$$
B=C_{r: n} \alpha \sum_{i=0}^{n-r}(-1)^{i}\left(\begin{array}{c}
n-r \\
i
\end{array}\right) \frac{1}{(r+i)(r+i+1)}
$$

when $\mathrm{P}=0.5$ in (4.1), we get the median of the distribution.

5. J oint Distribution of two Concomitants $y_{[r: n]}$ and $y_{[s: n]}$

For the Bivariate Inverse Rayleigh distribution using (1.7) and (1.8) in (1.3), then after lengthily integration and simplification, we get

$$
\begin{aligned}
& g_{[r, s: n]}\left(y_{1}, y_{2}\right)=8 C_{r, s: n} \frac{\theta_{2}^{2}}{y_{1}^{3} y_{2}^{3}} e^{-\theta_{2}\left[\frac{1}{\left.y_{1}^{2}+\frac{1}{y_{2}^{2}}\right]}\right.} \\
& \left.\sum_{i=0}^{s-r-1} \sum_{j=0}^{n-s}(-1)^{i+j}\left(\begin{array}{c}
s-r-1 \\
i
\end{array}\right) \begin{array}{c}
n-s \\
j
\end{array}\right) \\
& {\left[\frac{H\left(y_{1}, y_{2}\right)}{(s+j)(r+i)}-\frac{P\left(y_{1}, y_{2}\right)}{(s+j+1)(r+i+1)}-\frac{2 \alpha H\left(y_{2}\right)+2 \alpha^{2} H\left(y_{1}\right) H\left(y_{2}\right)}{(s-r-i+j+2)}+\frac{2 \alpha^{2} H\left(y_{1}\right) H\left(y_{2}\right)}{(s-r-i+j+3)}\right]}
\end{aligned}
$$

where

$$
\begin{aligned}
& H\left(\mathrm{y}_{1}\right)=1-2 \mathrm{e}^{-\frac{\theta_{2}}{\mathrm{y}_{1}^{2}}} \\
& \mathrm{H}\left(\mathrm{y}_{2}\right)=1-2 \mathrm{e}^{-\frac{\theta_{2}}{\mathrm{y}_{2}^{2}}} \\
& \mathrm{H}\left(\mathrm{y}_{1}, \mathrm{y}_{2}\right)=1+\alpha \mathrm{H}\left(\mathrm{y}_{1}\right)+\alpha \mathrm{H}\left(\mathrm{y}_{2}\right)+\alpha^{2} \mathrm{H}\left(\mathrm{y}_{1}\right) H\left(\mathrm{y}_{2}\right) \\
& \mathrm{P}\left(\mathrm{y}_{1}, \mathrm{y}_{2}\right)=2 \alpha \mathrm{H}\left(\mathrm{y}_{1}\right)+2 \alpha^{2} \mathrm{H}\left(\mathrm{y}_{1}\right) H\left(\mathrm{y}_{2}\right)
\end{aligned}
$$

and

$$
\mathrm{y}_{1}, \mathrm{y}_{2}, \theta_{2}>0,-1 \leq \alpha \leq 1
$$

6. Product moments of two Concomitants $y_{[r: n]}$ and $y_{[s: n]}$

The product moments of two concomitants $\mathrm{y}_{[r: n]}$ and $\mathrm{y}_{[s: n]}$ are given by

$$
E\left[y_{[r: n]}^{m} \cdot y_{[s: n]}^{n}\right]=\int_{0}^{\infty} \int_{0}^{\infty} y_{1}^{m} y_{2}^{n} g_{[r, s: n]}\left(y_{1}, y_{2}\right) d y_{1} d y_{2}
$$


putting the values of $g_{[r, s: n]}\left(y_{1}, y_{2}\right)$ from (5.1), integrating and after simplification, we get:

$$
\begin{aligned}
& E\left[y_{[r: n]}^{m} \cdot y_{[s: n]}^{n}\right]=2 C_{r, s: n} \theta_{2}^{\frac{m+n}{2}} \sqrt{1-\frac{m}{2}} \sqrt{1-\frac{n}{2}} \\
& \sum_{i=0}^{s-r-1} \sum_{j=0}^{n-s}(-1)^{i+j}\left(\begin{array}{c}
s-r-1 \\
i
\end{array}\right)\left(\begin{array}{c}
n-s \\
j
\end{array}\right) \\
& {\left[\frac{A_{1}}{(r+i)(s+j)}-\frac{A_{2}}{(r+i+1)(s+j+1)}-\frac{A_{3}}{(s-r-i+j+2)}+\frac{A_{4}}{(s-r-i+j+3)}\right]}
\end{aligned}
$$

where $\mathrm{m}, \mathrm{n}<2$ and

$$
\begin{aligned}
& \mathrm{A}_{1}=1+2 \alpha+\alpha^{2}-(1+\alpha) \alpha\left[2^{m / 2}+2^{n / 2}\right]+\alpha^{2} 2^{m+n / 2} \\
& \mathrm{~A}_{2}=2 \alpha(1+\alpha)-2 \alpha(1+\alpha) 2^{1+m / 2}-\alpha^{2} 2^{1+n / 2}\left[1-2^{m / 2}\right] \\
& \mathrm{A}_{3}=2 \alpha(1+\alpha)-2 \alpha\left[2^{n / 2}-\alpha 2^{m / 2}\right]-2 \alpha^{2}\left[2^{n / 2}-2^{m / 2}\right] \\
& \mathrm{A}_{4}=2 \alpha^{2}\left[1-2^{m / 2}-2^{n / 2}+2^{\frac{m+n}{2}}\right]
\end{aligned}
$$

\section{References}

1. Ahsanullah, M. and Navzoror, V.B., (2001), Ordered random variables, Nova sciences publishers, Inc New York.

2. Aleem, M. and Ahmed, M., (2003), Concomitants of Lower Record Values from Bivariate Inverse Rayleigh Distribution, Proc.Bio-Informatics I.T. \& Bio Stat. 135142. ISSOS, Lahore.

3. Anjuman, A.B. and khan, (1998), Concomitants of order statistics from Bivariate Pareto distribution, pos. Vol. 15(1), 65-77.

4. Ayesha, R. and Ahmad, M., (2001), Proc, ISSOS-VII Vol.12. 235-243, Lahore.

5. Bhatachariya, P.K. (1984), Induced order statistics, theory and application Handbook of statistics, 4. Eds: P.R. Krishnaiah and P.K. Sen, Elsevier, Amsterdam, 383-403.

6. David, H.A., (1973), Concomitants of Order Statistics, Bull. Internat. Statist. Inst. 45, 295-300.

7. David, H.A. and Nagaraga, H.N., (1998), Concomitants of order statistics, Handbook of statistics 16, Eds: N.Bala Kishnam \& C.R. Rao, Elsevier Amsterdam, 487-513.

8. Mukhergee, S.P. and Saran L.K., (1984), Bivariate Inverse Rayleigh Distribution in Reliability Studies, Journal of the Indian Statistical Association, Vol. 22, 23-31. 